\title{
Percutaneous Closure of Patent Foramen Ovale: A Case Series and Literature Review
}

Ravi K. Mareedu, MD; Milind S. Shah, MD; Juan E. Mesa, MD; and Charles S. McCauley, MD

\begin{abstract}
Patent foramen ovale (PFO) is an anatomical variant of the interatrial septum with an overall prevalence of $27 \%$ in autopsy studies. PFOs have a potential role in causation of stroke, platypneaorthodeoxia, decompression sickness, right to left shunt and migraine headaches. Data regarding percutaneous closure of PFO in low volume tertiary care centers is lacking. Retrospective review of 14 percutaneous PFO closures done in our facility from March 2005 to August 2006 was performed for efficacy of procedure and safety. All patients received clopidogrel for a period of 3 months, and aspirin and subacute bacterial endocarditis prophylaxis for 6 months. Mean age of the study population was 54 years. Fifty percent $(7$ of 14) of patients experienced an atrial septal aneurysm and 14\% (2 patients) exhibited a hypercoagulable state. The indication for closure in 13 patients was transient ischemic attacks or strokes, while one patient had persistent hypoxia due to a severe right to left shunt at PFO. Patients received either a CardioSEAL or Amplatzer device. Deployment rate was $100 \%$. All patients completed a minimum of 6 months of follow-up, with a mean follow-up time of $14.9 \pm 7.6$ months. No immediate or late bleeding complication occurred in any patient. One patient developed paroxysmal atrial fibrillation and one patient developed thrombotic complications at 7 months post-procedure secondary to the progression of her anal carcinoma and subsequently died. Pending the results of the four large randomized trials that are enrolling patients, percutaneous closure of PFO for cryptogenic strokes is an attractive alternative to lifelong anticoagulation with relatively few complications, even in low volume centers. There are many challenges in the management of this subset of patients, the foremost being the selection of a target patient population. Role of PFO in migraines is less clear.
\end{abstract}

Keywords: Amplatzer; ASA; CardioSEAL; Cryptogenic stroke; Patent foramen ovale; PFO

$\mathrm{P}$ the interatrial septum, which until recently was believed to be of no clinical importance. Evidence emerging over the past 15 years suggests a role for PFO in cryptogenic stroke, platypnea-orthodeoxia, decompression sickness, right to left shunt and migraine headaches. Better diagnostic modalities for its detection and improved methods of closure, including percutaneous approach have become available for clinical practice.

PFO is a congenital defect occurring in the septum separating the two atrial chambers. PFO provides communication between the atrial chambers of the heart through fossa ovalis on the right side and the ostium secundum on the left side. Septum primum acts as a one-way valve allowing blood flow from the right to left atria, bypassing the lungs. ${ }^{1}$ This septum normally remains patent

Reprint Requests: Milind S. Shah, MD, Interventional Cardiologist, Department of Cardiology, Marshfield Clinic, 1000 North Oak Avenue, Marshfield, WI 54449, Tel: 7I5-387-5460, Fax: 7I5-389-3808, Email: shah.milind@marshfieldclinic.org before birth and closes with the first breath of air that a baby takes because of increased left sided pressures. Anatomical closure usually occurs by 2 years of age. However, it remains patent in a subset of the population. Autopsy studies have shown an overall prevalence of $27 \%$ in the general population, decreasing with increasing age $(35 \%$ and $20 \%$ in age groups less than 30 years and more than 80 years, respectively). ${ }^{2}$ This could be secondary to either selective mortality of patients with PFO with age or late spontaneous closure. The average size is estimated at $4.9 \mathrm{~mm}$ with a majority of $<10 \mathrm{~mm}$ in size. ${ }^{2}$ Transthoracic echocardiographic diagnosis requires detection of a shunt with either color Doppler or agitated saline contrast with or without Valsalva maneuver, and its prevalence in the population varies anywhere between $10 \%{ }^{3}$ to $22 \%{ }^{4}$ with this technique.

Received: March 16, 2007

Revised: June 15, 2007

Accepted: June 27, 2007

doi: $10.3121 / \mathrm{cmr} .2007 .764$ 


\section{OBJECTIVE}

Our objective was to review the safety and efficacy of percutaneous closure of PFO in patients with TIAs or stroke on anti-coagulation or those presenting with significant hypoxia.

\section{METHODS}

Fourteen patients underwent PFO closure at our hospital between March 2005 and August 2006. The use of the CardioSEAL and Amplatzer device was approved by the Institutional Review Board. All patients (except one with hypoxia) were evaluated by a neurologist prior to evaluation for the causes of the strokes. All patients had an MRI, carotid Doppler's, transthoracic echocardiography (TTE)/ transesophageal echocardiography (TEE) with agitated saline contrast and pro-coagulation work-up (including protein $\mathrm{C}$ and $\mathrm{S}$, antithrombin III, factor V Leiden, antiphospholipid antibodies, lupus anticoagulant and/or homocysteine levels). In 13 of 14 patients, the indication for procedure was recurrent cryptogenic strokes/TIAs, while in one patient the indication was chronic symptomatic hypoxemia. The age of patients ranged from 36 to 73 years. Seven patients had associated atrial septal aneurysm (ASA), and 5 patients had significant recurring symptoms of migraine. Other demographics of the patients are detailed in table 1. Two patients presented with hypercoagulable states. Otherwise secondary workup was essentially negative in all patients. Success was defined as procedural success (deployment of device) in closure of the PFO and also absence of residual shunt on repeat echocardiograms, both immediate and late (6 months).

\section{PROCEDURE}

The procedure was done under fluoroscopic guidance with or without the use of an ultrasound. The procedure involved access via the modified Seldinger technique. French sheaths were introduced in femoral artery and vein. The positions of the PFO and atrial septum were reviewed by advancing an

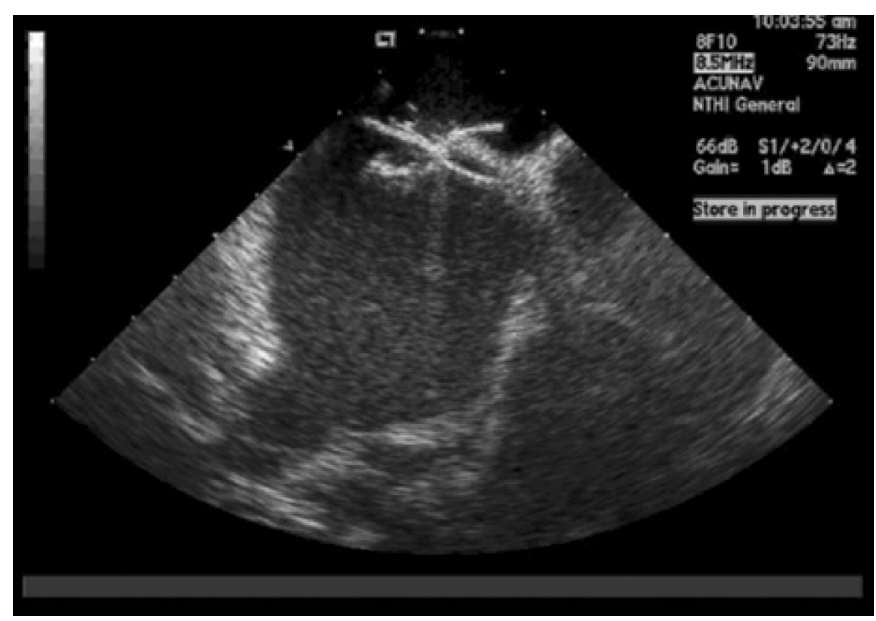

Figure 1. Intracardiac echocardiogram confirming device placement.

intracardiac echocardiogram catheter into the right atrium. All patients received a heparin bolus. A wire then was used to cross the PFO. The catheter was then advanced into the left upper pulmonary vein. An Amplatz wire was advanced into the left upper pulmonary vein. The catheter was then exchanged for a sizing balloon. Balloon sizing was done before echo and fluoroscopic evaluation. An intracardiac echocardiogram was used to get the diameter at full closure of the PFO. The size of the device to be used was based on these measurements. The balloon catheter was then exchanged with the delivery catheter for the CardioSEAL/Amplatzer device. The CardioSEAL/Amplatzer device was then advanced into the left atrium under both fluoroscopic guidance and intracardiac echocardiographic guidance, and the left atrial umbrella/disc was opened. The device was then pulled back to keep it snugly attached to the left atrial side of the intra-atrial septum and the right atrial umbrella/disc was released. Upon confirmation of the position and stability by fluoroscopy and intracardiac echocardiogram (figure1), the device was released successfully.

Table 1. Patient characteristics

\begin{tabular}{|c|c|c|c|c|c|c|c|c|c|c|c|c|c|c|}
\hline Patient & 1 & 2 & 3 & 4 & 5 & 6 & 7 & 8 & 9 & 10 & 11 & 12 & 13 & 14 \\
\hline Gender & $\mathrm{F}$ & $\mathrm{F}$ & $\mathrm{M}$ & $\mathrm{F}$ & $\mathrm{F}$ & $\mathrm{F}$ & $\mathrm{M}$ & $\mathrm{M}$ & $M$ & $\mathrm{~F}$ & $\mathrm{~F}$ & $\mathrm{M}$ & $\mathrm{F}$ & $\mathrm{F}$ \\
\hline Age & 58 & 53 & 68 & 74 & 65 & 36 & 72 & 40 & 41 & 49 & 60 & 44 & 37 & 60 \\
\hline Diabetes mellitus & - & Yes & - & - & - & - & Yes & - & - & - & Yes & - & - & - \\
\hline Hyperlipidemia & - & Yes & - & Yes & - & Yes & Yes & Yes & - & Yes & Yes & Yes & - & - \\
\hline Hypertension & Yes & Yes & - & - & Yes & - & Yes & - & - & Yes & Yes & Yes & - & Yes \\
\hline Smoking & Yes & - & - & - & - & - & - & - & - & - & Yes & - & Yes & - \\
\hline Coronary artery disease & Yes & Yes & Yes & - & - & - & Yes & - & - & - & Yes & - & - & Yes \\
\hline Migraine & - & - & - & Yes & Yes & - & - & - & - & Yes & - & - & Yes & Yes \\
\hline Atrial septal aneurysm & Yes & Yes & - & Yes & - & - & Yes & - & Yes & - & - & Yes & Yes & - \\
\hline Hypercoagulable state & - & - & Yes & - & - & - & Yes & - & - & - & - & - & - & - \\
\hline Indication & Hyp & R TIA & R TIA & R Str & $\mathrm{R}$ St & $\mathrm{R}$ St & R TIA & TIA & $\mathrm{R} \mathrm{St}$ & R TIA & St & TIA & R TIA & R TIA \\
\hline Device & CS & CS & CS & CS & AM & AM & CS & AM & AM & CS & CS & CS & CS & CS \\
\hline Diameter of device & $23 \mathrm{~mm}$ & $17 \mathrm{~mm}$ & 17 mm & $23 \mathrm{~mm}$ & $25 \mathrm{~mm}$ & $18 \mathrm{~mm}$ & $28 \mathrm{~mm}$ & $28 \mathrm{~mm}$ & $25 \mathrm{~mm}$ & $23 \mathrm{~mm}$ & $28 \mathrm{~mm}$ & $23 \mathrm{~mm}$ & $28 \mathrm{~mm}$ & $28 \mathrm{~mm}$ \\
\hline Follow-up time (months) & 10 & 22 & 7 & 24 & 24 & 27 & 18 & 24 & 7 & 13 & 6 & 8 & 6 & 13 \\
\hline Improvement in migraine & NA & NA & NA & NA & Yes & Yes & NA & NA & NA & Yes & NA & NA & Yes & Unknown \\
\hline Complications & Thrombus? & - & - & - & - & - & - & - & - & $\mathrm{AF}$ & - & - & - & - \\
\hline
\end{tabular}

AF, atrial fibrillation; AM, Amplatzer; CS, CardioSEAL; Hyp, hypoxia; -, no; NA, not applicable; St, Stroke; TIA, Transient Ischemic Attack; R TIA, Recurrent TIAs; R St, Recrrent Stroke 


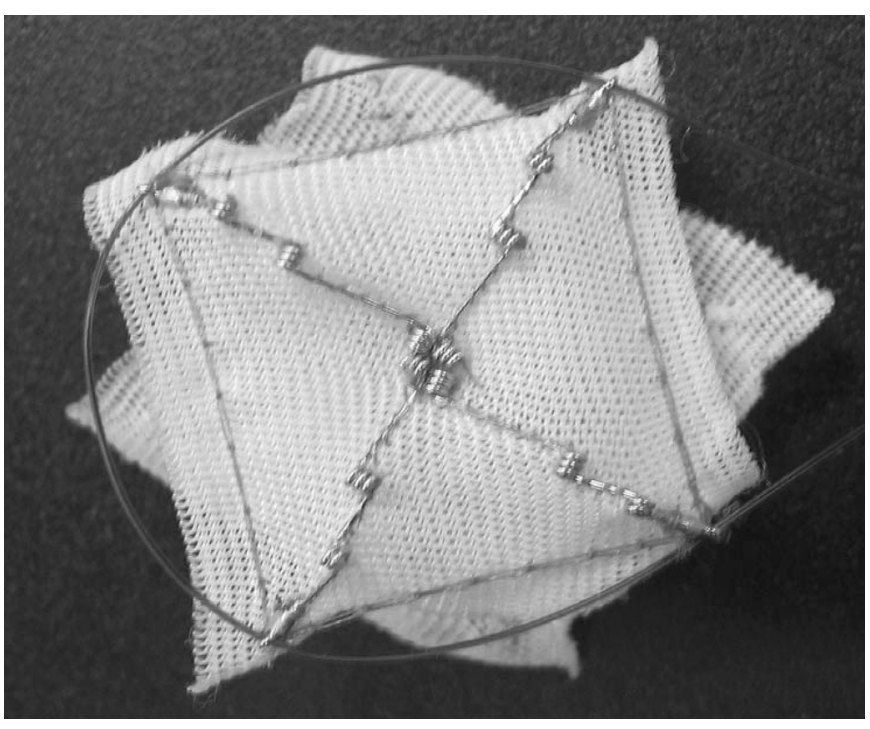

Figure 2. CardioSEAL device.

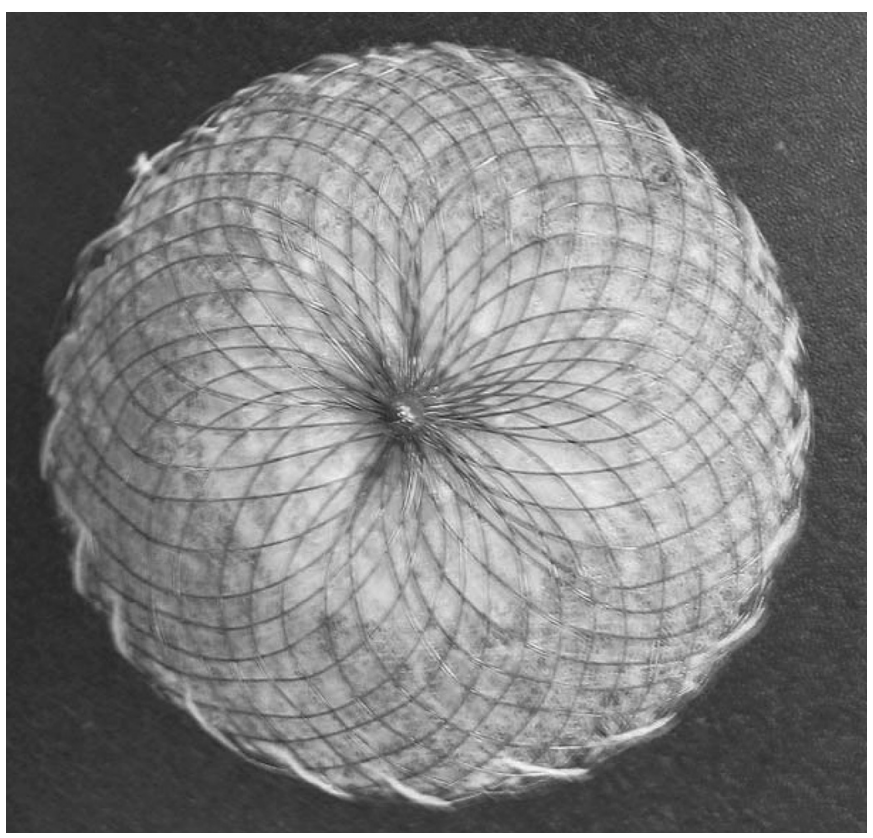

Figure 3. Amplatzer device.

\section{RESULTS \\ Immediate Results}

Successful closure of the PFO without any evidence of residual shunt was achieved in all patients without any complications including problems such as arrhythmias, stroke, myocardial infarction, bleeding, blood transfusion, emergency bypass, renal failure and allergies during, or immediately after, the procedure. All patients were discharged the day after procedure unless the patient had other medical co-morbidities unrelated to the procedure. All patients had a chest $\mathrm{x}$-ray and echocardiogram within 24 hours of the procedure to rule out pericardial effusions. As described, the CardioSEAL device (figure 2) was used in 10 patients and Amplatzer (figure 3) was used in the remaining 4 patients. The mean diameter of the device was $23.86 \mathrm{~mm}$.

\section{Follow-up}

All patients were followed, at a minimum, for 1 month and 6 months post-procedure. The mean follow-up time was $14.9 \pm 7.6$ months. Echocardiogram with bubble contrast was obtained 6 months post-procedure. All patients received the loading dose of Plavix in the catheterization laboratory and remained on Plavix for a period of 3 months, aspirin (325 mg) for 6 months and subacute bacterial endocarditis prophylaxis for 6 months.

None of the patients had any recurrence of stroke/paradoxical embolism. Four of five patients with migraines had complete relief of symptoms and one patient developed paroxysmal atrial fibrillation. One patient with anal carcinoma developed deep venous thrombosis, right atrial thrombus and right ventricular thrombus 7 months post-device placement. Her thrombus was presumed secondary to progression of anal carcinoma and she died shortly afterwards. No symptoms of endocarditis, effusion or inter-atrial shunt were noted in all other patients.

\section{EPIDEMIOLOGY}

Stroke is the third leading cause of death in the United States afflicting 700,000 patients each year. ${ }^{5}$ Of these, 200,000 are recurrent attacks. ${ }^{5}$ While a specific etiology can be found in approximately $60 \%$ to $70 \%$ of patients experiencing ischemic stroke, ${ }^{6,7}$ no etiology can be found in the remaining patients and these are appropriately termed "cryptogenic strokes." ${ }^{8}$ In the subset of patients less than 55 years of age, cryptogenic stroke accounts for about $64 \%$ of patients. ${ }^{9}$ Recurrence rate of all strokes is around $9.4 \%$ annually, and is $10 \%$ annually for cryptogenic stroke. ${ }^{10}$

PFO was linked to cryptogenic stroke as early as $1877,{ }^{11}$ and was first reported by Lechat et al in 1988 in a subset of the population. ${ }^{3}$ Sixty stroke patients younger than 55 years were compared to controls for the presence of PFO with contrast echocardiography. Ten percent of controls had PFO, while $40 \%$ of patients with stroke had PFO. This association jumped to $54 \%$ in patients with cryptogenic stroke. ${ }^{3}$ In contrast, Di Tullio et al reported a significant association in all age groups. ${ }^{12} \mathrm{~A}$ meta-analysis of all the studies for association of cryptogenic stroke, PFO and ASA found significant association between PFO and cryptogenic strokes in patients younger than 55 years but not above that age. ${ }^{13}$ However, these studies were subject to potential bias since the echocardiography reader was not blinded to the indication of the echocardiography. Those studies most subject to potential bias are diagnostic studies, where detection depends on the technique and thoroughness of the echocardiographer. ${ }^{14}$ A blinded study by Homma et al ${ }^{15}$ showed a significant association of cryptogenic stroke with PFO, and also demonstrated that larger PFOs had stronger association with stroke.

\section{PATHOPHYSIOLOGY OF STROKE IN PFO}

PFO has a general prevalence of $27 \%$ but stroke occurs only in a small fraction of this population. The incidence rate of 
cryptogenic stroke among populations with PFOs is only 1 in $1000 .{ }^{16}$ Although many mechanisms of causation of stroke in patients with PFO have been postulated, there are still unanswered questions.

Paradoxical embolism through PFO is postulated to be the primary mechanism. Several findings in this subset of patients support this hypothesis:

1. Right to left shunt has been shown to occur with normal atrial pressures in Valsalva maneuver (after release phase), during coughing, during mechanical ventilation and with increased right atrial pressure from pulmonary embolism, chronic lung disease and right heart failure. ${ }^{17,18}$ Stroke patients have higher rates of PFO patency at rest without any induction maneuvers. ${ }^{19}$

2. Deep vein thrombosis is detected only in a small percentage of patients with cryptogenic stroke, ${ }^{20}$ but this prevalence is definitely higher when compared to controls with stroke of determined origin or no stroke. Delay in performing diagnostic Doppler studies has been implicated in failure to detect deep venous thrombosis in a higher percentage of populations. ${ }^{14}$ Brain tissue is more sensitive to ischemia. Therefore, small embolic fragments $(1 \mathrm{~mm}$ in diameter) too small to cause pulmonary embolism can cause brain infarction. ${ }^{8}$

3. Size of PFO and amount of shunting had a direct correlation with the prevalence of cryptogenic stroke 21,22 as opposed to stroke with determined causes or normal controls. Surprisingly size of PFO had no relation to the recurrence rates of strokes. ${ }^{15}$

Other postulated mechanisms for stroke include in situ thrombus formation secondary to stasis of blood in the PFO canal based on observations in TEE or surgery or at autopsy. ${ }^{19}$ Atrial arrhythmias, although postulated as a possible cause, are rare in patients with PFO and stroke, unlike the presence of atrial septal defects which predispose patients to atrial fibrillation. ${ }^{14}$

The definition of cryptogenic stroke was established in the Trial of Org 10172 in Acute Stroke Treatment (TOAST) study, where the term cryptogenic stroke was applied if a brain infarction could not be attributed to any specific category of cardioembolism, large artery atherosclerosis or small artery disease even after extensive evaluation that included imaging, cardiac and serologic studies. ${ }^{23}$ Thus, the workup of these patients should include brain imaging with computerized tomography (CT) or magnetic resonance imaging (MRI), vascular imaging including carotid Doppler's, and angiography (magnetic resonance or CT or conventional). Cardiac workup should include electrocardiogram (EKG), Holter monitoring and echocardiography or TEE assessment. Other basic labs like complete blood count, electrolytes, fasting lipids, fasting glucose, $\mathrm{HgbA} 1_{c}$, serology for syphilis (venereal disease research laboratory, rapid plasma reagin) and hypercoagulability workup that includes protein $\mathrm{C}$ and $\mathrm{S}$, antithrombin III, factor V Leiden, antiphospholipid antibodies, lupus anticoagulant and homocysteine levels are also obtained. ${ }^{24}$ Although the risk of atherosclerotic disease is low in young patients, evaluation can be tailored to evaluate other causes of stroke.

\section{MIGRAINE AND PFO}

Studies have shown an association of PFO with migraines. Retrospective analysis in patients where PFO was corrected showed significant resolution or improvement of migraine symptoms. ${ }^{25-29}$ Higher correlation of migraines with aura compared to migraines without aura were reported in patients with PFO. PFO may have played a role in the transport of small paradoxical emboli to the vertebro-basilar system and was associated with increased levels of vasoactive chemicals (including amines, and atrial natriuretic peptide) reaching cerebral circulation through bypass of pulmonary circulation through the shunt. ${ }^{30}$ At the 2006 annual meeting of the American College of Cardiology, preliminary findings of the Migraine Intervention with STARFlex Technology trial (MIST) reported a $42 \%$ incidence of a $50 \%$ reduction in headache days when comparing patients with device closure as per their headache days before closure and during followup. The respective reduction in the sham-placebo patients was $23 \% \quad(P=0.038)$. However, a preliminary endpoint for complete resolution of headache was not achieved. ${ }^{31}$

\section{DIVING AND PFO}

The possibility of neurological decompression sickness being related to PFO was not advanced until the late 1980s and early 1990s because of the complex physiology involved in both conditions. Retrospective studies performed since then have shown an increased prevalence of PFO in divers with decompression sickness compared with controls. Odds ratio (OR) of experiencing decompression sickness when diving with PFO was postulated to be 2.6.32 The mechanism postulated to underlie decompression sickness in divers involves bypass of the pulmonary filter through the shunt.

\section{DIAGNOSIS OF PFO}

Initial screening is done with TTE using color Doppler and agitated saline contrast. ${ }^{33}$ Trans-cranial Doppler examinations with Valsalva and bubble test can also be used as an initial screning test (has higher sensitivity, lower specificity than TTE). The agitated saline contrast study with TEE and Valsalva maneuver is the gold standard test for the detection of PFOs. Saline contrast is a first-generation contrast agent first described in the late 1960s. ${ }^{34}$ As opposed to second-generation contrast agents, air contrasts can only opacify the right heart. Bottled saline with benzyl alcohol is used to increase the half-life of air bubbles. ${ }^{33}$ Dedicated echocardiographic contrast media are available which are easier to handle, but costly. Micro-bubbles larger than 8 microns become fractured due to the size of the pulmonary capillaries through which they pass and are subsequently 


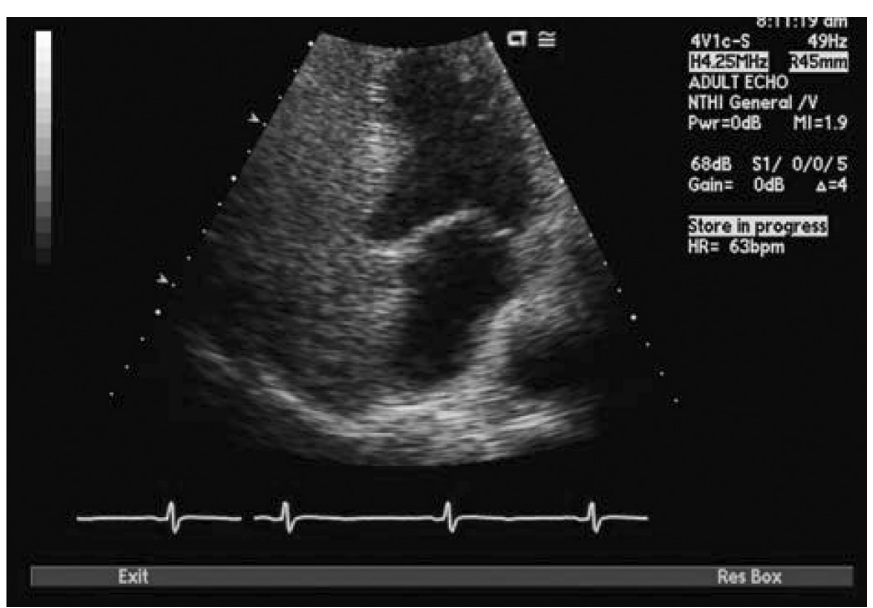

Figure 4. Transthoracic echocardiogram (TTE) with bubbles in right atrium.

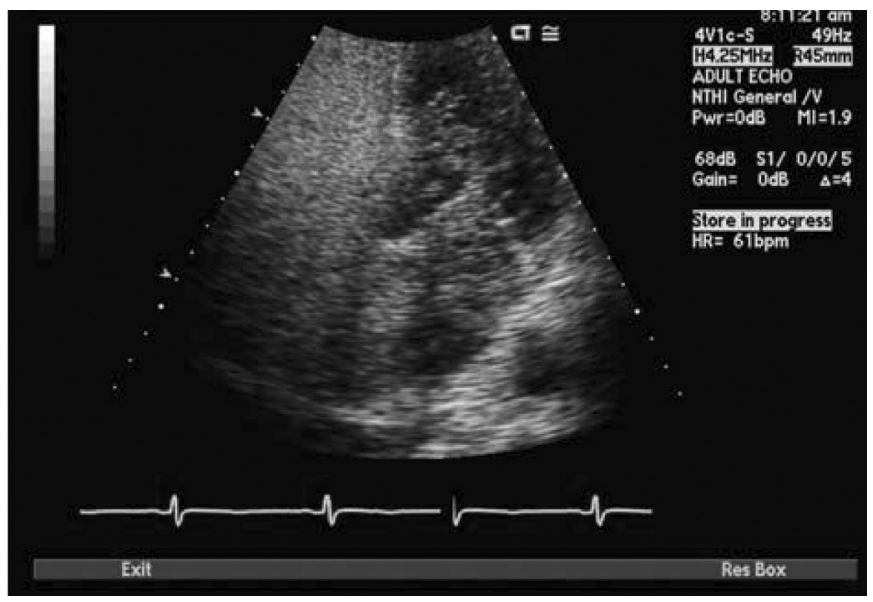

Figure 5. TTE depicting passage of saline contrast from RA to LA across a PFO.

dissolved in approximately 0.19 seconds. Pulmonary transit time is somewhat longer at 1.6 seconds when compared to the time taken for dissolution. ${ }^{35}$ Thus, no bubble should be seen on the left side of the heart and any bubbles present would be too small to be seen by fundamental imaging. Subsequent development of second harmonic imaging for TTE has indeed detected some micro-bubbles due to improvements in visualization technology. ${ }^{35}$

With TTE, the apical 4-chamber view or subcostal windows are used for visualization of contrast in the right heart and appearance of contrast (even one bubble) in the left atrium in 3 cardiac cycles is indicative of intracardiac shunt, while the appearance of contrast after 3 cardiac cycles is indicative of intra-pulmonary shunt. ${ }^{35}$ Maneuvers like Valsalva, deep inspiration or cough may be needed to increase the sensitivity of the test. Administration of contrast through the femoral vein as opposed to the ante-cubital vein has shown to increase sensitivity of detection of PFO. This is due to the fact that blood from the superior vena cava is directed towards the tricuspid valve, while venous return from the inferior vena cava is directed towards the PFO. ${ }^{34,35}$
TEE is done for all borderline TTE studies or in patients with a high clinical suspicion of PFO with normal TTE. Size of PFO can be evaluated and the amount of shunt can be indirectly noted based on the number of bubbles appearing in the left atrium. Mild shunting corresponds to less than 5 bubbles, moderate shunting 5 to 25 bubbles and marked shunting greater than 25 bubbles. ${ }^{34}$ Figures 4 and 5 show evidence of PFO with multiple bubbles shunting into the left atrium from the right atrium. Color Doppler depicting evidence of shunt via PFO is shown in figure 6.

Recent advances in technology, including harmonic imaging, have increased the sensitivity of TTE for the detection of PFO. Ha et $\mathrm{al}^{36}$ demonstrated that TTE with harmonic imaging has a sensitivity of $62.5 \%$ and specificity of $100 \%$ in comparison with TEE as the gold standard. The advantage of using TTE is that it is less invasive compared to TEE and maneuvers during imaging are performed easily because the patient is not sedated. Advantages of TEE include the fact that it is the gold standard for the detection of PFO, and it allows for evaluation of foramen ovale orifice, ostium secundum, interatrial septum and ASA (figures 7 and 8). ${ }^{34}$

\section{TREATMENT OPTIONS}

Treatment of patients with PFO and cryptogenic strokes is complicated because there are no large randomized controlled trials comparing efficacy of various treatment modalities including medical management (antiplatelet therapy versus anticoagulation with warfarin), percutaneous closure of PFO or surgical closure. However, evidence-based literature has provided some insights.

\section{Medical Management}

Aspirin is believed to play a role in management by preventing the formation of platelet or fibrin aggregates that are responsible for paradoxical embolism. Mas et al ${ }^{37}$ showed that the risk of recurrent strokes in patients with isolated PFO and cryptogenic stroke treated with aspirin is comparable to patients with no PFO or ASA (2.3\% vs. $4.2 \%$ ). However, the

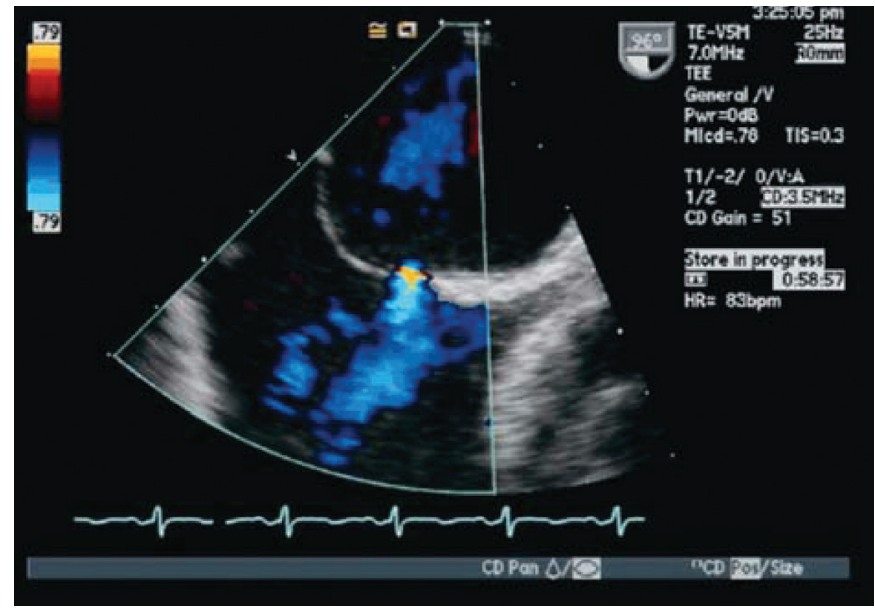

Figure 6. Transesophageal echocardiography (TEE) with color Doppler showing evidence of blood flow from left to right atrium across a PFO. 


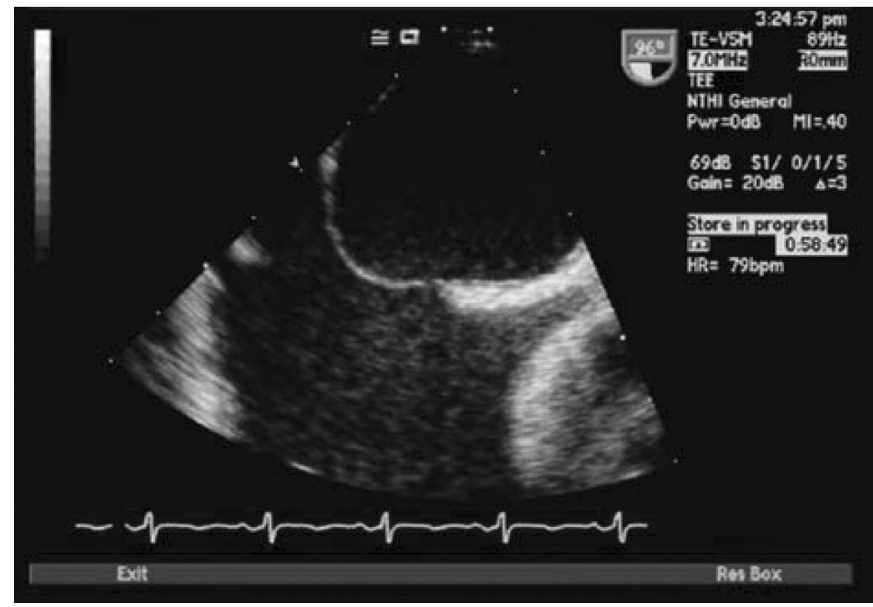

Figure 7. TEE with morphological representation of atrial septal aneurysm with evidence of bulging of the septum from the left atrium to the right atrium.

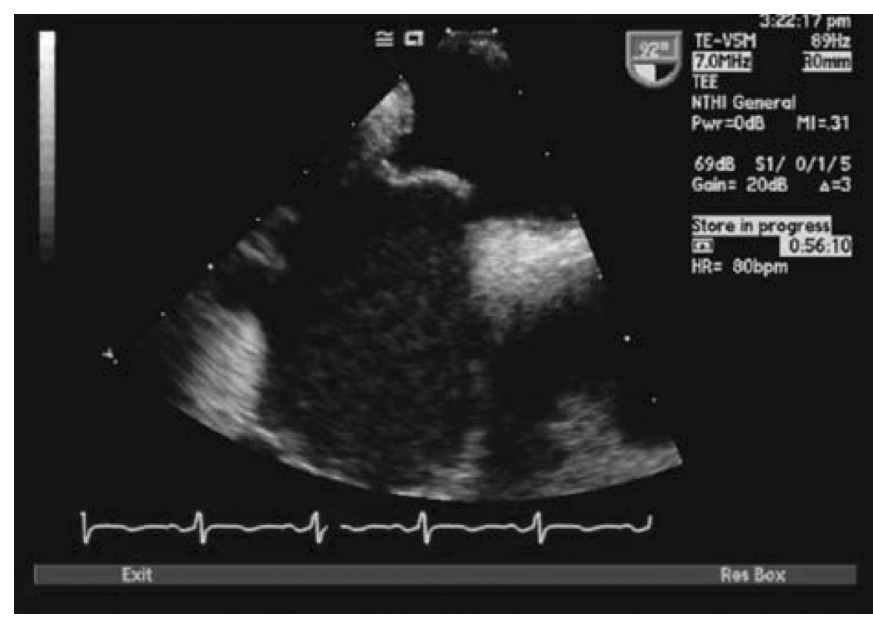

Figure 8. TEE with morphological representation of paradoxical septal motion associated with paradoxical embolism in cryptogenic stroke.

recurrence rate was high in the group of patients with both PFO and ASA (15.2\%, 95\% confidence interval [CI], 1.8 to 28.6). A meta-analysis of five retrospective cohort studies showed that warfarin was superior to aspirin in preventing recurrent strokes in patients with PFO and stroke (OR 0.37, $95 \%$ CI, 0.23 to 0.60 ), while surgical closure was comparable to warfarin use for the same purpose (OR 1.19, 95\% CI, 0.62 to 2.27). ${ }^{38}$ On the other hand, investigators of the Patent Foramen Ovale in Cryptogenic Stroke Study (PICSS) comparing warfarin versus aspirin use in patients with $\mathrm{PFO}$ and stroke (either cryptogenic or known sub-type) reported no difference in incidence of recurrent strokes between groups. ${ }^{15}$

Another study involving 92 patients failed to show a difference between warfarin and aspirin use in similar subgroups of populations. ${ }^{39}$ However, limitations of these studies included inadequate sample size, inadequate follow-up and lack of homogeneity among comparison groups, preventing comparison of their outcomes with other studies.

\section{Mechanical Closure}

Surgical treatment

Direct closure of the PFO was evaluated in a few studies which had varied results. Dearani et al ${ }^{40}$ followed 91 patients for 2 years after direct closure of PFO and found that $92.5 \%$ and $83.4 \%$, respectively were free of transient ischemic attack (TIA)/stroke at the end of 1 year and 2 years. The only risk factor predicting the recurrence was occurrence of multiple TIA/strokes prior to the procedure..$^{40}$

In a study by Devuyst et al, ${ }^{41}$ surgical closure of PFO in patients less than 60 years of age with a high risk of recurrence (e.g., recurrent TIA/strokes, $\mathrm{PFO}$ with ASA, $>50$ micro bubbles in left atrium on contrast studies, Valsalva maneuver/cough preceding stroke) found no evidence of TIA/strokes at the end of the 2-year follow-up. ${ }^{41}$

Homma et al ${ }^{42}$ published data in 28 patients treated with surgical closure. At 13 months of follow-up, a 19.5\% recurrence of events (strokes/TIAs) in all patients was noted. None of the patients less than 45 years of age (17 patients) experienced recurrence, while 4 of the 11 patients aged 45 years or above experienced recurrence of events. ${ }^{42}$

The surgical approach is associated with significant morbidity (around 21\%) in the form of atrial fibrillation, infection, bleeding or tamponade. ${ }^{40}$ The associated mortality rate of atrial septal defect closures by thoracotomy is around $1.5 \% .43$

\section{Percutaneous trans-catheter closure}

Secundum atrial septal defect closure via percutaneous transvenous approach was first attempted in 1975.44 The first case series reporting the successful transcatheter closure of PFO in 36 patients was published in 1992.45 Subsequently, the results with closure devices are associated with improved outcomes.

Schrader ${ }^{46}$ reported one of the largest series of PFO transcatheter closures involving 457 patients (169 with ASA) from 1994 to 2003 . Thirteen percent of 277 patients who completed the 6 month follow-up had a residual shunt, while $6.5 \%$ of 111 patients had residual shunt at the 12 month follow-up. The rate of event recurrence including stroke/TIAs was $1.9 \%$ per year. ${ }^{46}$ With reference to complications, no wire fractures occurred in devices used since 2000,3\% developed thrombi that were transient and 4 patients developed pericardial effusions. ${ }^{46}$ In a different case series involving closure in 1000 patients with either atrial septal defect or PFO, thrombus was seen in only 20 patients. ${ }^{47}$

There are no randomized controlled trials that compare medical therapy versus percutaneous closure in patients with PFO. Recently, a nonrandomized, prospective, patient preference case series comparing antiplatelet therapy 
(44 patients) and percutaneous closure (48 patients) was published. ${ }^{48}$ All patients had at least 2 years of follow-up. The recurrence rates of embolic events in the medical therapy group and percutaneous closure group were $14.75 \%$ and $0 \%$, respectively ( $<<0.001$ ). In the PFO group, all patients had complete closure at 6 months and had no complications. In contrast, $6 \%$ and $13 \%$ of patients in the antiplatelet group had major and minor hemorrhagic events, respectively.

Currently, there are four randomized multicentric trials that are enrolling patients for the comparison of percutaneous closure of PFO with the medical therapy. They include the Randomized Evaluation of Recurrent Stroke Comparing PFO Closure to Established Current Standard of Care Treatment (RESPECT) trial (sponsored by AGA Medical) and Patent Foramen Ovale and Cryptogenic Embolism (PC) trial (sponsored by AGA Medical) involving the use of the Amplatzer device, ${ }^{49}$ CLOSURE I trial (sponsored by NMT Medical) evaluating the use of STARFlex septal occluder, ${ }^{49}$ and Cardia PFO trial (sponsored by Cardia Inc) involving the use of PFO Star device. ${ }^{49}$

\section{Guidelines from Societies}

With absence of randomized controlled trials comparing the different options of therapy, there are no clearly-defined guidelines from any professional societies. The American College of Cardiology, American Heart Association and American Society of Echocardiography have no recommendations with reference to PFO management. The American College of Neurology reports that there is insufficient evidence to evaluate efficacy of surgical or endovascular closure.

\section{FUTURE ROLE OF PROCEDURE}

The percutaneous closure is associated with very few complications compared to the surgical closure involving thoracotomy. Percutaneous closure offers a viable alternative to pharmacological treatment, if benefits are seen in randomized controlled trials. Success and outcomes of PFO percutaneous closure in a low volume center has been reported in one other study recently. ${ }^{50}$ In addition, the quality of devices used for closure has improved rapidly in the past decade, with decreasing incidence of in situ thrombus formation noted at the device site. ${ }^{48}$ There are many challenges in the management of this subset of patients, the foremost being the selection of a target patient population. The benefit of PFO closure in older patients should be evaluated by better studies because they are prone to atherosclerosis and thrombogenesis in the left side of the heart, rendering any attempt at preventing strokes via PFO closure ineffective. ${ }^{46}$ In spite of the increasing use of percutaneous closure in patients, well-designed randomized controlled trials comparing medical therapy and surgical closure with percutaneous closure are needed before this procedure becomes a standard of care accepted by all physicians.

\section{IMPACT ON CARE}

The impact of PFO closures on health care systems and patients' lives should be addressed in a systematic way taking into consideration the frequent recurrence of strokes and their devastating impact on patients. The cost-to-benefit ratio of the procedure should be considered relative to quality-of-life improvement achieved by prevention of one stroke. In addition, costs incurred by the healthcare system in association with multiple evaluations and hospital admissions for each recurrence of stroke are formidable. The same arguments apply to promoting the procedure for treatment of patients with migraines. In the coming years, percutaneous closure is expected to gain wider acceptance and application, if the ongoing randomized trials do show a significant benefit compared to other modalities of treatment.

\section{ACKNOWLEDGMENTS}

The authors thank Marshfield Clinic Research Foundation for its support through the assistance of Linda Weis and Alice Stargardt in the preparation of this manuscript.

\section{REFERENCES}

1. Gill EA Jr. Definitions and pathophysiology of the patent foramen ovale: broad overview. Cardiol Clin 2005;23:1-6.

2. Hagen PT, Scholz DG, Edwards WD. Incidence and size of patent foramen ovale during the first 10 decades of life: an autopsy study of 965 normal hearts. Mayo Clin Proc 1984;59:17-20.

3. Lechat P, Mas JL, Lascault G, Loron P, Theard M, Klimczac M, Drobinski G, Thomas D, Grosgogeat Y. Prevalence of patent foramen ovale in patients with stroke. N Engl J Med 1988;318:1148-1152.

4. Hausmann D, Mugge A, Becht I, Daniel WG. Diagnosis of patent foramen ovale by transesophageal echocardiography and association with cerebral and peripheral embolic events. Am J Cardiol 1992;70:668-672.

5. Stroke statistics. American Heart Association Web site. Available at: http://www.americanheart.org/presenter.jhtml?identifier $=472$ 5. Accessed April 11, 2006.

6. Sacco RL, Ellenberg JH, Mohr JP, Tatemichi TK, Hier DB, Price TR, Wolf PA. Infarcts of undetermined cause: the NINCDS Stroke Data Bank. Ann Neurol 1989;25:382-390.

7. Mohr JP, Thompson JL, Lazar RM, Levin B, Sacco RL, Furie KL, Kistler JP, Albers GW, Pettigrew LC, Adams HP Jr, Jackson CM, Pullicino P; Warfarin-Aspirin Recurrent Stroke Study Group. A comparison of warfarin and aspirin for the prevention of recurrent ischemic stroke. N Engl J Med 2001;345:1444-1451.

8. Mohr JP. Cryptogenic stroke. N Engl J Med 1988; 318:1197-1198.

9. Cabanes L, Mas JL, Cohen A, Amarenco P, Cabanes PA, Oubary P, Chedru F, Guerin F, Bousser MG, de Recondo J. Atrial septal aneurysm and patent foramen ovale as risk factors for cryptogenic stroke in patients less than 55 years of age. A study using transesophageal echocardiography. Stroke 1993;24:1865-1873.

10. Sacco RL, Shi T, Zamanillo MC, Kargman DE. Predictors of mortality and recurrence after hospitalized cerebral infarction in an urban community: the Northern Manhattan Stroke Study. Neurology 1994;44:626-634.

11. Cohnheim J. Thrombose und embolie. Vorlesung , ber allgemeine Pathologie. Berlin, Hirschwald 1877;1:134. 
12. Di Tullio M, Sacco RL, Gopal A, Mohr JP, Homma S. Patent foramen ovale as a risk factor for cryptogenic stroke. Ann Intern Med 1992;117:461-465.

13. Overell JR, Bone I, Lees KR. Interatrial septal abnormalities and stroke: a meta-analysis of case-control studies. Neurology 2000;55:1172-1179.

14. Kizer JR, Devereux RB. Clinical practice. Patent foramen ovale in young adults with unexplained stroke. $\mathrm{N}$ Engl $\mathrm{J}$ Med 2005;353:2361-2372.

15. Homma S, Sacco RL, Di Tullio MR, Sciacca RR, Mohr JP; PFO in Cryptogenic Stroke Study (PICSS) Investigators. Effect of medical treatment in stroke patients with patent foramen ovale: patent foramen ovale in Cryptogenic Stroke Study. Circulation 2002;105:2625-2631.

16. Lock JE. Patent foramen ovale is indicted, but the case hasn't gone to trial. Circulation 2000;101:838.

17. Langholz D, Louie EK, Konstadt SN, Rao TL, Scanlon PJ. Transesophageal echocardiographic demonstration of distinct mechanisms for right to left shunting across a patent foramen ovale in the absence of pulmonary hypertension. J Am Coll Cardiol 1991;18:1112-1117.

18. Pell AC, Hughes D, Keating J, Christie J, Busuttil A, Sutherland GR. Brief report: fulminating fat embolism syndrome caused by paradoxical embolism through a patent foramen ovale. $\mathrm{N}$ Engl J Med 1993;329:926-929.

19. Horton SC, Bunch TJ. Patent foramen ovale and stroke. Mayo Clin Proc 2004;79:79-88.

20. Falk RH. PFO or UFO? The role of a patent foramen ovale in cryptogenic stroke. Am Heart J 1991;121:1264-1266.

21. Hausmann D, Mugge A, Daniel WG. Identification of patent foramen ovale permitting paradoxic embolism. J Am Coll Cardiol 1995;26:1030-1038.

22. Homma S, Di Tullio MR, Sacco RL, Mihalatos D, Li Mandri G, Mohr JP. Characteristics of patent foramen ovale associated with cryptogenic stroke. A biplane transesophageal echocardiographic study. Stroke 1994;25:582-586.

23. Adams HP Jr, Bendixen BH, Kappelle LJ, Biller J, Love BB, Gordon DL, Marsh EE 3rd. Classification of subtype of acute ischemic stroke. Definitions for use in a multicenter clinical trial. TOAST. Trial of Org 10172 in Acute Stroke Treatment. Stroke 1993;24:35-41.

24. Bailey CE, Allaqaband S, Bajwa TK. Current management of patients with patent foramen ovale and cryptogenic stroke: our experience and review of the literature. WMJ 2004;103:32-36.

25. Del Sette M, Angeli S, Leandri M, Ferriero G, Bruzzone GL, Finocchi C, Gandolfo C. Migraine with aura and right-to-left shunt on transcranial Doppler: a case-control study. Cerebrovasc Dis 1998;8:327-330.

26. Lamy C, Giannesini C, Zuber M, Arquizan C, Meder JF, Trystram D, Coste J, Mas JL. Clinical and imaging findings in cryptogenic stroke patients with and without patent foramen ovale: the PFO-ASA Study. Atrial Septal Aneurysm. Stroke 2002;33:706-711.

27. Sztajzel R, Genoud D, Roth S, Mermillod B, Le Floch-Rohr J. Patent foramen ovale, a possible cause of symptomatic migraine: a study of 74 patients with acute ischemic stroke. Cerebrovasc Dis 2002;13:102-106.

28. Wilmshurst PT, Nightingale S, Walsh KP, Morrison WL. Effect on migraine of closure of cardiac right-to-left shunts to prevent recurrence of decompression illness or stroke or for haemodynamic reasons. Lancet 2000;356:1648-1651.

29. Morandi E, Anzola GP, Angeli S, Melzi G, Onorato E. Transcatheter closure of patent foramen ovale: a new migraine treatment? J Interv Cardiol 2003;16:39-42.
30. Beda RD, Gill EA Jr. Patent foramen ovale: does it play a role in the pathophysiology of migraine headache? Cardiol Clin 2005;23:91-96.

31. Wilmshurst P, Dowson AJ, Muir KW, Mullen M, Nightingale S, MIST Investigators. A prospective, multicenter, randomized, double blind, placebo-controlled trial to evaluate the efficacy of patent foramen ovale closure with the STARFlex septal repair implant to prevent refractory migraine headaches: the MIST Trial. Paper presented at: ACC 55th Annual Scientific Session; March 13, 2006; Atlanta, GA.

32. Germonpre P. Patent foramen ovale and diving. Cardiol Clin 2005;23:97-104.

33. Gill EA Jr, Quaife RA. The echocardiographer and the diagnosis of patent foramen ovale. Cardiol Clin 2005; $23: 47-52$.

34. Gramiak R, Shah PM, Kramer DH. Ultrasound cardiography: contrast studies in anatomy and function. Radiology 1969;92:939-948.

35. Woods TD, Patel A. A critical review of patent foramen ovale detection using saline contrast echocardiography: when bubbles lie. J Am Soc Echocardiogr 2006;19:215-222.

36. Ha JW, Shin MS, Kang S, Pyun WB, Jang KJ, Byun KH, Rim SJ, Huh J, Lee BI, Chung N. Enhanced detection of right-toleft shunt through patent foramen ovale by transthoracic contrast echocardiography using harmonic imaging. Am J Cardiol 2001;87:669-671, A11.

37. Mas JL, Arquizan C, Lamy C, Zuber M, Cabanes L, Derumeaux G, Coste J; Patent Foramen Ovale and Atrial Septal Aneurysm Study Group. Recurrent cerebrovascular events associated with patent foramen ovale, atrial septal aneurysm, or both. N Engl J Med 2001;345:1740-1746.

38. Orgera MA, O'Malley PG, Taylor AJ. Secondary prevention of cerebral ischemia in patent foramen ovale: systematic review and meta-analysis. South Med J 2001;94:699-703.

39. Bogousslavsky J, Garazi S, Jeanrenaud X, Aebischer N, Van Melle G. Stroke recurrence in patients with patent foramen ovale: the Lausanne Study. Lausanne Stroke with Paradoxal Embolism Study Group. Neurology 1996;46:1301-1305.

40. Dearani JA, Ugurlu BS, Danielson GK, Daly RC, McGregor CG, Mullany CJ, Puga FJ, Orszulak TA, Anderson BJ, Brown RD Jr, Schaff HV. Surgical patent foramen ovale closure for prevention of paradoxical embolism-related cerebrovascular ischemic events. Circulation 1999;100(19 Suppl): II171-II175.

41. Devuyst G, Bogousslavsky J, Ruchat P, Jeanrenaud X, Despland PA, Regli F, Aebischer N, Karpuz HM, Castillo V, Guffi M, Sadeghi H. Prognosis after stroke followed by surgical closure of patent foramen ovale: a prospective follow-up study with brain MRI and simultaneous transesophageal and transcranial Doppler ultrasound. Neurology 1996;47:1162-1166.

42. Homma S, Di Tullio MR, Sacco RL, Sciacca RR, Smith C, Mohr JP. Surgical closure of patent foramen ovale in cryptogenic stroke patients. Stroke 1997;28:2376-2381.

43. Nendaz MR, Sarasin FP, Junod AF, Bogousslavsky J. Preventing stroke recurrence in patients with patent foramen ovale: antithrombotic therapy, foramen closure, or therapeutic abstention? A decision analytic perspective. Am Heart J 1998;135:532-541.

44. King TD, Thompson SL, Steiner C, Mills NL. Secundum atrial septal defect. Nonoperative closure during cardiac catheterization. JAMA 1976;235:2506-2509.

45. Bridges ND, Hellenbrand W, Latson L, Filiano J, Newburger JW, Lock JE. Transcatheter closure of patent foramen ovale after presumed paradoxical embolism. Circulation 1992;86:1902-1908.

46. Schrader R. Indication and techniques of transcatheter closure of patent foramen ovale. J Interv Cardiol 2003;16:543-551. 
47. Krumsdorf U, Ostermayer S, Billinger K, Trepels T, Zadan E, Horvath K, Sievert H. Incidence and clinical course of thrombus formation on atrial septal defect and patient foramen ovale closure devices in 1,000 consecutive patients. J Am Coll Cardiol 2004;43:302-309.

48. Thanopoulos BV, Dardas PD, Karanasios E, Mezilis N. Transcatheter closure versus medical therapy of patent foramen ovale and cryptogenic stroke. Catheter Cardiovasc Interv 2006;68:741-746.

49. Homma S, Sacco RL. Patent foramen ovale and stroke. Circulation 2005;112:1063-1072.

50. Aslam F, Iliadis AE, Blankenship JC. Percutaneous closure of patent foramen ovale: success and outcomes of a low-volume procedure at a rural medical center. J Invasive Cardiol 2007;19:20-24

\section{AUTHOR AFFILIATIONS}

Ravi K. Mareedu, MD

Department of Internal Medicine

Marshfield Clinic

1000 North Oak Avenue

Marshfield, Wisconsin 54449

Milind S. Shah, MD

Department of Cardiology

Marshfield Clinic

1000 North Oak Avenue

Marshfield, Wisconsin 54449

Juan E. Mesa, MD

Department of Cardiology

Marshfield Clinic

1000 North Oak Avenue

Marshfield, Wisconsin 54449

Charles S. McCauley, MD

Department of Cardiology

Marshfield Clinic

1000 North Oak Avenue

Marshfield, Wisconsin 54449 